\title{
A Comparative Analysis of the Use of Different Zone Models to Predict the Mass Smoke Flow for Axisymetric and Spill Plumes
}

\author{
${ }^{(1)}$ IAIN SANDERSON, ${ }^{(1)}$ TONY KILPATRICK and ${ }^{(2)}$ JOSE TORERO \\ ${ }^{(1)}$ School of Built and Natural Environment \\ Glasgow Caledonian University \\ (2) BRE Centre for Fire Safety Engineering \\ The University of Edinburgh
}

\begin{abstract}
Sanderson [1] examined the theoretical basis for and the experimentation supporting the predictive smoke zone models currently being used in fire engineering design that are cited, in nationally and internationally accepted guidance documents, to support the increasing use of performance-based building codes/regulations throughout the world.

This critical examination identified anomalies: 1) between different researcher's results, when considering the same fire environment, and 2) areas where the models used in guidance documents have limited empirical support. The variance between models was examined by the parametric variation of critical data input parameters the impact of which indicated that the most recent research produced models that predict a lower level of mass smoke flow than the earlier models. It may be suggested that the more recent research, building on previous work, produces models that can be used with a greater level of confidence however there is no robust evidence to support this.
\end{abstract}

This paper illustrates the variances between the model outputs by means of a case study.

Currently there is a move towards the use of Computational Fluid Dynamic modelling of fire. However, given the limited validation of these models in the area of smoke movement and the computer time and power required to run these models, there is still a place in fire engineering design for the zone model.

As an increasing number of countries adopt performance building and fire codes/regulations and given the consequent need for predictive mass smoke flow models in which regulators, fire engineers and society can have confidence, it is concluded that the research supporting zone modelling of fire should be extended. This research should be robust and transparent in order to either produce models that are substantially more acceptable than those currently being used or to provide more confidence in models.

KEYWORDS: modelling, performance-based design, smoke management, smoke, reliability

\section{NOMENCLATURE LISTING}

\begin{tabular}{|c|c|c|c|}
\hline$c_{p}$ & $\begin{array}{l}\text { Specific heat at constant pressure } \\
(\mathrm{kJ} / \mathrm{kgK})\end{array}$ & $\delta M$ & Total mass smoke flow $(\mathrm{kg} / \mathrm{s})$ \\
\hline$d_{b}$ & $\begin{array}{l}\text { Depth of smoke layer below } \\
\text { balcony }(\mathrm{m})\end{array}$ & $\dot{\mathrm{Q}}$ & $\begin{array}{l}\text { Convective heat release rate } \\
(\mathrm{kW})\end{array}$ \\
\hline$g$ & Gravitational force $\left(9.81 \mathrm{~m} / \mathrm{s}^{2}\right)$ & $Q^{\prime}$ & $\begin{array}{l}\text { Convective heat release rate } \\
(\mathrm{kW})\end{array}$ \\
\hline$H$ & Height of opening (m) & $Q_{c}$ & $\begin{array}{l}\text { Convective heat release rate } \\
(\mathrm{kW})\end{array}$ \\
\hline$h_{\text {comp }}$ & Height of compartment (m) & $w$ & $\begin{array}{l}\text { Width of opening (m) } \\
\text { Height of rise to smoke to }\end{array}$ \\
\hline$h_{o}$ & Height of opening (m) & $Y$ & $\begin{array}{l}\text { underside of smoke layer (m) } \\
\text { Height of rise to smoke to }\end{array}$ \\
\hline$L$ & Width of spill edge (m) & $y$ & $\begin{array}{l}\text { underside of smoke layer (m) } \\
\text { Height of rise to smoke to }\end{array}$ \\
\hline$M^{\prime}$ & Mass smoke flow (kg/s) & $z$ & underside of smoke layer (m) \\
\hline$M_{v}$ & Mass smoke flow (kg/s) & $z_{l}$ & Limiting flame height (m) \\
\hline$M_{B}$ & $\begin{array}{l}\text { Mass smoke flow under a } \\
\text { balcony }(\mathrm{kg} / \mathrm{s})\end{array}$ & $z_{o}$ & $\begin{array}{l}\text { Height of virtual origin of } \\
\text { plume }(\mathrm{m})\end{array}$ \\
\hline
\end{tabular}

FIRE SAFETY SCIENCE-PROCEEDINGS OF THE NINTH INTERNATIONAL SYMPOSIUM, pp. 751-762 


\begin{tabular}{|c|c|c|c|}
\hline$M_{w}$ & $\begin{array}{l}\text { Mass smoke flow at opening } \\
(\mathrm{kg} /)\end{array}$ & Greek & \\
\hline$\dot{\mathrm{m}}$ & Mass smoke flow $(\mathrm{kg} / \mathrm{s})$ & $\alpha$ & Fire growth rate \\
\hline$\dot{\mathrm{m}}_{\rho}$ & $\begin{array}{l}\text { Mass smoke flow equations } 1 \& \\
2(\mathrm{~kg} / \mathrm{s})\end{array}$ & $\rho$ & Density of a gas $\left(\mathrm{kg} / \mathrm{m}^{3)}\right.$ \\
\hline$T_{\infty}$ & $\begin{array}{l}\text { Ambient Temperature equation } 1 \\
(\mathrm{~K})\end{array}$ & Subscr & ipts \\
\hline$T$ & Absolute temperature $(\mathrm{K})$ & $o$ & Ambient air \\
\hline$t$ & Time (s) & & \\
\hline
\end{tabular}

\section{INTRODUCTION}

Traditionally fire safety within buildings, both nationally and internationally, has been implemented within a prescriptive regulatory framework. Within this framework components of buildings are identified and standards are prescribed for the identified components. The prescriptive approach has been characterized as stifling innovative design; not being cost effective; offering no guidance on the acceptability or equivalency; and leading to the construction of some buildings with inappropriate fire safety measures. [2], [3]

The alternative to a prescriptive regulatory framework is to use a holistic approach where "the building is considered as a complex system, with the fire safety design just one of the many interrelated sub-systems" [2] The holistic approach to fire safety design requires that the risk be assessed and the protection afforded by the fire safety measures analysed. It deals with the performance of the building in the context in which it is utilised.

Performance-based building codes have been advocated as providing a regulatory framework where architects can be allowed to develop and implement innovative designs whilst maintaining an acceptable level of fire safety. It is also suggested that with the greater scientific understanding of fire the current level of fire safety may be achieved at reduced costs or a higher level of fire safety provided at the same cost. The potential for financial savings whilst achieving regulatory compliance are matters that have a clear attraction to building developers [4], [5], [6] All systems for performance-based regulation of fire safety rely heavily on the ability to predict the results of various fire scenarios. Where the critical variables are simple and known or discernible, the use of predictive models is relatively easy.[7] However predicting the relatively undefined problem of fire safety is more difficult as there is little or no control over the potential variables and there may be inadequate understanding of the underlying physical laws.

The models used as predictive tools are risk models with hazard models being a sub part of the risk model. The hazard models have received criticism for the inconsistency of results between different models used to address the same physical fire environment. [8], [9] Sanderson [10] also identified anomalies in the outputs of hazard models used by the regulators in various countries when the different models were applied to the same building.

In a fire it is critical that escape is possible prior to the exit routes being rendered untenable. Predominantly, untenability occurs either directly or indirectly due to the production of smoke. In this context smoke is taken to be both the particulate and gaseous products of combustion, including any air that comprises a large volume of the smoke plume and any subsequent smoke layer.[11],[12], [13] It can be concluded that the validity of the computational deterministic models relating to the production of smoke are of prime concern in relation to life safety within buildings.

\section{AXISYMETRIC FIRE PLUMES}

During the combustion process, materials are heated, usually by adjacent material already involved in the combustion process, and hot volatiles are given off. These volatiles ignite on reaching their flashpoint and create, above the fire, a rising column of flames and hot smoky gases. As a result of this upward movement of the products of combustion, air is entrained into the ensuing plume.

A portion of the oxygen in the entrained air will contribute to the combustion of flammable volatiles within the plume, but the majority of the air will be mixed with the hot smoky products of combustion and form a large proportion of the plume volume. 
In the early 1940's petrol fire plumes rising out of ditches beside airfield runways were used in the UK to entrain and remove fog. [14] Sir Geoffrey Taylor using his knowledge of fluid dynamics developed this wartime fog clearing system. Critical to the understanding of fire plumes is an appreciation of the amount of air entrained into the rising plume. According to Nelson [14] the initial work on defining fire plumes and the entrainment coefficient was published by Schmidt in 1941 and Taylor's analysis of this work was published as "Dynamics of a Mass of Hot Gas Rising in Air".

In 1956 Morton et al [15] published the first major publication of plume theory having a bearing on the analysis of accidental fires. This paper, "Turbulent Gravitational Convection from Maintained and Instantaneous Sources" describes the first heat-driven plume equation that included entrainment plume velocity and plume temperatures.

The equation produced by Morton et al described an idealised axisymetric plume, with a 'top-hat profile.

$$
\dot{\mathrm{m}}_{\rho}=0.20\left(\frac{\rho_{\infty}^{2} \mathrm{~g}}{\mathrm{c}_{\mathrm{p}}^{\mathrm{T}}}\right)^{\frac{1}{3}} \dot{\mathrm{Q}}^{\frac{1}{3}} \mathrm{z}^{\frac{5}{3}}
$$

This equation for axisymetric plumes was subsequently developed by others.

Zukoski et al [16] carried out several experiments measuring the plume mass flow at various heights and, using the ideal plume theory, developed Morton et al's equation to:

$$
\dot{\mathrm{m}}_{\rho}=0.21\left(\frac{\rho_{\infty}^{2} \mathrm{~g}}{\mathrm{c}_{\mathrm{p}} \mathrm{T}_{\infty}}\right)^{\frac{1}{3}} \dot{\mathrm{Q}}^{\frac{1}{3}} \mathrm{z}^{\frac{5}{3}}
$$

This only varies slightly from the theoretical equation however Zukoski et al [16] use $\alpha=0.11$ for no radiation loss whereas Quintiere and Grove [17] use a value of 0.098 for $\alpha$ which is closer to the value of 0.093 adopted by Morton et al [15].

Karlsson and Quintiere [18] state that based on the assumption that the constant ambient air properties are: $-$

$$
\mathrm{T}_{\infty}=293 \mathrm{~K}, \rho_{\infty}=1.1 \mathrm{~kg} / \mathrm{m}^{3}, \mathrm{c}_{\mathrm{p}}=1.0 \mathrm{~kJ} /(\mathrm{kgK}) \text { and } \mathrm{g}=9.81 \mathrm{~m} / \mathrm{s}^{2}
$$

the equation can be expressed as:

$$
\dot{\mathrm{m}}=0.071 \dot{\mathrm{Q}}^{\frac{1}{3}} \mathrm{z}^{\frac{5}{3}}
$$

This is the equation for entrainment into an axisymetric plume used in CIBSE Guide E and NFPA 92B. Both these guides, based on research by Zukoski et al [19], use an entrainment rate of half that for a fire twice the size for a fire against a wall and one quarter that for a fire four times the size for a fire in a corner.

Heskestad [20], [21], [22], [23], examines Fire Plumes, Flame Height and Air Entrainment and proposes a set of equations in relation to the axisymetric plume that limit or remove three of the main assumptions in relation to the 'ideal plume'. 
In relaxing the point source assumption as the origin of the plume he introduces the concept of a 'virtual origin' at some height $z_{o}$ above or below the actual fire taking into account that some of the plume properties are dependant on the convective energy release rate. A Gaussian profile replaces the 'top hat' profile across the plume for velocity and temperature. The Boussinesq approximation is removed to take account of large density differences. The concept of the plume density being approximately equal to ambient air density is removed.

Heskested produced the equations: -

For entrainment in the far field and,

$$
\begin{aligned}
& \text { for } z \geq z_{1} \\
& \dot{\mathrm{m}}=0.071 \mathrm{Q}_{\mathrm{c}}^{\frac{1}{3}}\left(\mathrm{z}-\mathrm{z}_{\mathrm{o}}\right)^{\frac{5}{3}} \times\left[1+0.026 \mathrm{Q}^{\frac{2}{3}}\left(\mathrm{z}-\mathrm{z}_{\mathrm{o}}\right)^{\frac{-5}{3}}\right]
\end{aligned}
$$

For entrainment in the near field.

$$
\begin{aligned}
& z<z_{1} \\
& \dot{\mathrm{m}}=\frac{0.0054 \mathrm{Q}_{\mathrm{c}} \mathrm{z}}{\left(0.166 \mathrm{Q}_{\mathrm{c}}^{\frac{2}{5}}+\mathrm{z}_{\mathrm{o}}\right)}
\end{aligned}
$$

Thomas et al [24] carried out research into venting fires in single compartment structures following the fire in the Jaguar Motors Plant in England. This work produced two equations - one for small fires and one for large fires.

The flow of hot gases into the smoke layer at ceiling level for small fire is based on the work by Yih (1952) and follows the theory put forward by Morton et al [15] that the fire is regarded as a plume of hot gases which behaves as though it originated from a point source located below the fire.

The expression produced for small fires, near field was: -

$M=0.153 \rho_{c}\left[\frac{Q_{c} g}{\rho_{c} C_{p} T_{o}}\right]^{\frac{1}{3}} r_{b} 5 / 3$

Thomas et al [24] found that an adequate theoretical description of entrainment into large fires could not be produced. They therefore relied on empirical data produced by Rouse, H et al [25]; Ricou and Spalding [26] and Rasbash et al [27] to produce the expression: -

$$
\mathrm{M}=0.096 \mathrm{P}_{\rho} \mathrm{y}^{(3 / 2)} \rho_{\mathrm{o}}\left(\mathrm{g} \frac{\rho_{\mathrm{o}}}{\rho}\right)^{1 / 2}+\mathrm{RA}_{\mathrm{f}}
$$

The effect of the fuel flow, $\mathrm{RA}_{\mathrm{f}}$ was found to be negligible [28] and dropped and substituting for other variables reduces the equation to:

$\mathrm{M}=0.188 \mathrm{PY}^{3 / 2}$ 
Variables substituted:

$1.22 \mathrm{~kg} / \mathrm{m}^{3}$ at $17^{\circ} \mathrm{C}$ for density of ambient air $\left(\rho_{\mathrm{o}}\right)$

$290 \mathrm{~K}$ for absolute temperature of ambient air $\left(\mathrm{T}_{\mathrm{o}}\right)$

$1100 \mathrm{~K}$ for absolute temperature of flames in smoke plume $(\mathrm{T})$

$9.81 \mathrm{~m} / \mathrm{s}^{2}$ for acceleration due to gravity

Hansell [28] hypothesized, based on experimental work by Zukoski [19], that in order to take account of the geometric and positional variances influencing the fire plume development that this equation should have correction factors applied.

(a) Very large spaces (high Ceilings)

$$
\mathrm{C}_{\omega}=1.0, \mathrm{C}_{\mathrm{s}}=1.0, \mathrm{C}_{\mathrm{j}}=1.0 \Rightarrow 0.19 \mathrm{PY}^{3 / 2}
$$

(b) Very large space/room (low ceilings)

$$
\mathrm{C}_{\omega}=1.1, \mathrm{C}_{\mathrm{s}}=1.0, \mathrm{C}_{\mathrm{j}}=1.0 \Rightarrow 0.21 \mathrm{PY}^{3 / 2}
$$

(c) Smaller rooms

$$
\mathrm{C}_{\omega}=1.28, \quad \mathrm{C}_{\mathrm{s}}=1.0, \mathrm{C}_{\mathrm{j}}=1.4 \Rightarrow 0.39 \mathrm{PY}^{3 / 2}
$$

Where $C_{\omega}$ is the plume tilt correction factor; $C_{s}$ is the wall proximity correction factor and $C_{j}$ is the wall jet correction factor.

Hansell [19] states that the above hypothesis is based on the assumption that the effects of aerodynamic disturbance, wall proximity wall jet and wall convection that had been validated for small fires, can equally apply to large fire plumes.

Equations 8, 9, 10 and 11 are used in BR 368 for entrainment into plumes above large fires.

\section{SPILL PLUMES}

A calculation method devised by Morgan and Marshall [29] was revised by Morgan [30], with reference to the horizontal flow of smoke towards the opening and by Morgan and Hansell [31] to extend the methods applicability to include adhered spill plumes. This is known as the BRE Spill Plume method

The BRE Spill Plume Calculation is a complicated method but as stated by Morgan et al [32] is suitable for all geometric configurations where the mass flow of smoke in a large volume space is being considered for a fire originating in an adjacent room. Sanderson [1] questioned the validity of this statement.

Given the complexity of the BRE Spill Plume Method, a number of simplified spill plume equations have been developed. The currently available simplified spill plume equations generally assume that the spill plume is generated from a virtual line source, having no width, located some distance below the spill edge.

Using a relationship developed by Lee and Emmons [33] to determine the distance of the virtual plume source beneath the spill edge Thomas [34] developed the single line equation: -

$\mathrm{M}_{\mathrm{V}}=0.58 \rho\left(\frac{\mathrm{gQL}^{2}}{\rho \mathrm{cT}}\right)^{\frac{1}{3}}(\mathrm{z}+\Delta)\left(1+\frac{0.22(\mathrm{z}+2 \Delta)}{\mathrm{L}}\right)^{\frac{2}{3}}$

Where

$$
\Delta=\mathrm{D}_{\mathrm{b}}+\frac{\mathrm{M}_{\mathrm{B}}}{\mathrm{CQ}^{\frac{1}{3}}}
$$


Poreh et al [35], assuming that the volumetric flow of the ambient air per unit length of the plume in the far field is a function of the buoyant flux per unit length and the distance from the virtual source, deduced a relationship between the mass flow rate for a line plume and the convective heat output of the gases. Incorporating work done by Lee and Emmons 1961 and Marshall and Harrison 1996 Poreh et al produced the equation for free spill plumes: -

$$
M_{v}=Q^{\frac{1}{3}} C\left(z+d_{b}+\frac{M_{b}}{C Q^{\frac{1}{3}}}\right)
$$

Thomas et al [36] provided the following simplified spill plume equation that is only applicable to free spill plumes rising into large area smoke reservoirs.

$\mathrm{M}^{\prime}=1.2 \mathrm{M}_{\mathrm{B}}^{\prime}+0.16 \mathrm{zQ}^{\frac{1}{3}}+0.0027 \mathrm{Q}^{\prime}$

Taking an empirically derived relationship, inherent in Poreh et al's spill plume equation [35], Thomas et al produced equation 15 , which is taken as a suitable alternative to equation 14 [36].

$\mathrm{M}^{\prime}=1.4 \mathrm{M}_{\mathrm{B}}^{\prime}+0.16 \mathrm{ZQ}^{\frac{1}{3}}+0.0014 \mathrm{Q}^{\prime}$

Thomas et al [36] also proposed that the volume of air entrained into the free ends of the spill plume can be quantified as:

$\delta \mathrm{M}=0.09 \mathrm{z}\left(\frac{\mathrm{Q}}{\mathrm{L}}\right)^{\frac{1}{3}}$

The results of equations 15 and 16 can then be combined to give the mass flow of gases for a free spill plume, including entrainment at the free ends of the plume.

The BRE Spill Plume and equations 12, 13, 15 and 16 are used in BR 368, which is referenced in the UK Building Regulations.

By correlating the empirical data produced by Morgan and Marshall [29], [37] and assuming that $\rho \approx \rho_{1} \approx 1.25$, Law [38] further simplified the spill plume formula to:

$\mathrm{M}_{\mathrm{V}}=0.34\left(\mathrm{QL}^{2}\right)^{\frac{1}{3}}\left(\mathrm{~d}_{1}+0.15 \mathrm{H}\right)$

A variant on this equation, equation 18 below that is used in CIBSE Guide E, CIBSE TM19 and NFPA92B.

$M_{v}=0.36 Q_{p} \frac{1}{3}{ }_{c}^{\frac{2}{3}}\left(z_{b}+0.25 h\right)$ 
Harrison [39], using $1 / 10^{\text {th }}$ scale modelling, produced a simplified spill plume equation to predict the mass flow rate of gases due to a free spill plume, including entrainment of air into the ends of the plume:

$$
\mathrm{M}_{\mathrm{p}}=0.20 \mathrm{Q}^{\frac{1}{3}} \mathrm{~W}^{\frac{2}{3}} \mathrm{z}+0.0017 \mathrm{Q}+1.5 \mathrm{M}_{\mathrm{b}}
$$

This empirical correlation only applies to a flow which is channelled, where the width of the compartment opening is the same as that at the spill edge and where the approach flow is under a flat ceiling or a deep downstand at the spill edge.

In calculating the mass flow of smoke under the balcony Harrison derived, from results of modelling using Fire Dynamics Simulator (FDS), the equation: -

$$
\mathrm{M}_{\mathrm{b}}=0.89\left(\frac{\mathrm{h}_{\mathrm{o}}}{\mathrm{w}_{\mathrm{o}}}\right)^{-0.92}\left(\frac{\mathrm{h}_{\mathrm{comp} \mathrm{M}_{\mathrm{w}}}}{\mathrm{w}_{\mathrm{o}}}\right)
$$

However Harrison and Spearpoint [40] revert to the more often used $\mathrm{M}_{\mathrm{b}}=2 \mathrm{M}_{\mathrm{w}}$ for this value.

\section{DESIGN FIRES}

Design fires are either steady state or growing fires.

Following experimentation Hinkley [41] proposed a steady state design fire size of 5MW for sprinkler controlled retail premises, where the sprinklers are standard response (RTI $>50 \mathrm{~m}^{1 / 2} \mathrm{~s}^{1 / 2}$ ) and this is used in NFPA 92B, CIBSE Guide E and BR 368. For fast response sprinklers 2.5MW has been proposed [42]. [43]However, this has not been universally accepted [44]

Growing fires are generally based on an $\alpha t^{2}$ fire growth with the value of $\alpha$ being determined by the time taken for the fire to grow to $1000 \mathrm{~kW}$. The fire size that is then used for design purposes is that where growth is stopped by some form of intervention. (e.g. sprinkler actuation.)

In AS 1668.3 a polynomial variant of $\alpha \mathrm{t}^{2}$ is used to more appropriately model the initial growth phase. [45] The fire growth is taken to an intervention point and then equation 7 , excluding the fuel flow rate, is used to determine the mass smoke flow.

\section{CASE STUDY}

For the case study BR 368, NFPA 92B, and AS 1668.3 were used. Additionally, as it involves the most recent research, the method proposed by Harrison is used. [40]

The building to be examined in the case study is Centre West, East Kilbride. Centre West Shopping Centre has approximately 40 units trading on a two-storey mall that connects to the west side of the existing Plaza development. There is a mezzanine level above the northern section of the level 1 Food Court. The mezzanine level overlooks a three-storey void but is only accessible from the Food Court Level. There is a large shop unit at the west end of the mall. There is car parking at ground, first, second and third floor levels and at intermediate levels.

The shop units are separated from each other by fire resisting construction but the frontages onto the mall are of non-fire resisting glazing. The food court is open to the mall on both the first floor and mezzanine levels and the seating areas extend beyond the fire separating walls between the shop units.

All the shop units are provided with a life safety sprinkler system designed and installed in compliance with BS 5306 Part 2 1990. The sprinkler heads are quick response heads with a response time index (RTI) of $<50 \mathrm{~m}^{1 / 2} \mathrm{~s}^{1 / 2}$ designed to contain the fire size to $2.5 \mathrm{MW}$. In line with the requirements of the Technical 
Standards for Compliance with the Building Standards (Scotland) Regulations $1990,5^{\text {th }}$ amendment, no sprinklers are provided in the mall as the mall height is greater than $10 \mathrm{~m}$.

The smoke control system is designed to maintain the smoke layer height $3.7 \mathrm{~m}$ above the finished floor level of the first floor balcony. Channelling screens are provided to the underside of the Upper Retail Mall floor slab. These are positioned so that no channel width will be greater than $17 \mathrm{~m}$. They are positioned $2.25 \mathrm{~m}$ above finished floor level in the Lower Retail Mall,

Shop front treatment is provided to any shop that opens onto two smoke zones in order to prevent smoke flowing into more than one zone.

This has been achieved by making the shop unit frontage which faces onto one of the zones 30 minutes fire resistant, or by providing a deep downstand or smoke curtain on the shop front to channel smoke flow from the shop.

The mass smoke flow in the large shop unit was calculated using the axisymmetric calculation appropriate to the guidance being considered and the flow of smoke into the atrium space was calculated using the spill plume calculation.

\section{METHOD USED IN CENTRE WEST}

The smoke control system was designed using, in the main, the guidance of BR 368. However, the fire engineering consultants stated that the spill plume from the underside of the balcony to the upper edge of the balcony edge safety barriers was an adhered plume and above that to the smoke layer the plume was adhered. This meant that the plume temperature was higher than it would have been if the plume had been treated as a free spill plume throughout its height of rise to the smoke layer.

This approach was used in comparison with the other methods where those methods also included calculation for an adhered plume.

\section{Results}

The outputs from the application of the different methods for the production of axisymmetric and spill plume mass flow are shown in Tables 1 and 2.

It should be noted that only the BRE Spill Plume and CIBSE TM19 includes the adhered plume rise of 1.6 metres in the calculation. Applied to the other methods, this would s decrease the mass smoke flow.

Table 1. Spill Plume Mass Smoke Flow Predictions

\begin{tabular}{|l|l|l|l|l|l|l|}
\hline Method & $\begin{array}{l}\text { BRE Spill } \\
\text { Plume }\end{array}$ & $\begin{array}{l}\text { CIBSE } \\
\text { TM19 }\end{array}$ & NFPA 92B & Thomas 87 & $\begin{array}{l}\text { Thomas et } \\
\text { al 98 }\end{array}$ & Harrison \\
\hline $\begin{array}{l}\text { Mass Smoke } \\
\text { Flow }\end{array}$ & $122 \mathrm{kgs}^{-1}$ & $135 \mathrm{kgs}^{-1}$ & $166 \mathrm{kgs}^{-1}$ & $129 \mathrm{kgs}^{-1}$ & $93 \mathrm{kgs}^{-1}$ & $100 \mathrm{kgs}^{-1}$ \\
\hline
\end{tabular}

Table 2. Axisymetric Plume Mass Smoke Flow Predictions

\begin{tabular}{|l|l|l|l|l|}
\hline Method & BR 368 & CIBSE TM19 & NFPA 92B & AS 1668.3 \\
\hline Mass Smoke Flow & $9.84 \mathrm{kgs}^{-1}$ & $8.79 \mathrm{kgs}^{-1}$ & $10.5 \mathrm{kgs}^{-1}$ & $5.7 \mathrm{kgs}^{-1}$ \\
\hline
\end{tabular}

The outputs characterize the variance between the methods when applied in practice. As would be expected there is very good correlation between the spill plume predicted mass flow using the BRE Spill Plume and Thomas 87.

The AS1668: 3 method for axisymmetric plumes for the large shop unit shows the impact of the lower heat release rate which can be considered as providing a reduced safety margin. 
There is significant variance between the predictions of different models being used to predict the mass flow of smoke. This uncertainty exists whether the model is simple or complex. The level of complexity of the BRE Spill Plume calculation could, to some, infer a greater level of accuracy.

The use of Computational Fluid Dynamic models is increasing as they are seen as having a greater level of accuracy particularly when analysing smoke flows in complex geometries. However, the data input demands, computer time and memory required are significant. Further the uncertainties associated with the input assumptions and problems with validation are inherently the same as for zone models. [46]. [47]

The need to provide engineers and regulators with predictive models that they can, within the constraints of experimental uncertainty; use with confidence is not currently met.

\section{CONCLUSION}

It is therefore concluded that zone models continue to provide a useful tool for informing fire engineering analysis and decision making

Therefore further experimental analysis of smoke flows by scale modelling and full size modelling, supported by the use of validated computational fluid dynamics modelling is required. Harrison [39] is undertaking this research at the University of Canterbury in New Zealand.

The scale modelling experiments should take account of the various geometrical features and other factors that will influence the extent of entrainment into the plume. The following factors derived from the research by Sanderson [1] should be taken into account in future research:

- The entrainment into the axisymetric plume taking account of fire size in relation to the enclosure in which it is located, including wall/corner proximity and flow of air around the fire;

- The effect on the mass flow of smoke when the width and height of the opening is varied;

- The influence on the mass flow of smoke as it spreads under a balcony both where there are, and where there are no, channelling screens;

- The variance in entrainment as smoke flows under balconies of varying width;

- The impact of downstands at the opening from the room of fire origin and at balcony spill edge;

- The size of the fire being considered.

To ensure robustness and reproducibility the scale experiments should be repeated 'blind'. Subsequently full scale modelling should be carried out to determine any scale anomalies.

Appraisal of the scale experimental results by CFD modelling may be difficult as the scale models currently used have their derivation in the appraisal of zone models dealing with fire on a macro scale whereas CFD models deal with fire on a micro scale. However, comparison of the CFD modelling of the full scale results, separately and by those having no knowledge of the results of the full scale tests, would provide further information regarding the appropriateness of the use of CFD models in the prediction of mass smoke flow.

\section{REFERENCES}

[1] Sanderson, I. A. , The Validity and Applicability of Fire Models Used to Predict the Production of Smoke Within the Built Environment PhD Thesis, Glasgow Caledonian University, Glasgow 2007.

[2] Stollard, P., Fire Safety Engineering in Design Against Fire Ed Stollard and Johnston E \&FN Spon London, 1994

[3] Johnson, Peter The benefits of Fire Safety Engineering to Building Design in Fire Safety Engineering Vol 4 Number 1 February 1997 pp 9\&10, 1997

[4] Beck, V. R. Fire Safety System Design Using Risk Assessment Models: Developments in Australia Fire Safety Science - Proceedings of the Third International Symposium Cox Geoffrey and Langford Brian eds. Elsevier Science Publishers Ltd Barking1991 
[5] Puchovsky Milosh NFPA's Perspectives on Performance-Based Codes and Standards in Fire Technology Vol 3 No4 pp 323-332. 1996

[6] Averill, Jason D. Performance-Based Codes: Economics, Documentation and Design Worcester Polytechnic Institute, Worcester 1998

[7] Brannigan, V. et al Regulatory Requirements For Performance Based Codes Using Mathematical Risk Assessment Conference Proceedings of the Seventh International Interflam Conference Interscience Communications Limited London.1996

[8] Butcher Gordon E and Parnell Alan C Smoke Temperature for Smoke Control Design Fire Safety Engineering Vol 1 No 4 pp21-23 1994

[9] Butcher Gordon E and Parnell Alan C96 “Fire Engineering Solutions” Fire Safety Engineering Vol 3No 4 pp24-251996

[10] Sanderson I Smoke Control in Enclosed Shopping Malls - A Comparative Analysis Undergraduate Dissertation. Glasgow Caledonian University 1999

[11] NFPA 92B ${ }^{\circledR}$ Guide for Smoke Management Systems in Malls, Atria and Large Areas National Fire Protection Association Quincy MA 2000

[12] Building Code of Australia-Performance 1996

[13] BR368 Design Methodologies for Smoke and Heat Exhaust Ventilation Building Research Establishment Ltd Garston 1999

[14] Nelson Harold E. From Phlogiston to Computational Fluid Dynamics Fire Protection Engineering Issue No. 13 pp 9-17. 2002

[15] Morton B R, Taylor, Geoffrey and Turner, J S Turbulent Gravitational Convection From Maintained and Instantaneous Sources Proceedings of the Royal Society of London. Cambridge University Vol 234 No 1196 pp1-23. 1956

[16] Zukoski E.E., Kubota, T and Cetegen, B. Entrainment in Fire Plumes Fire Safety Journal 1980/1981 Vol 3 pp 107-121 1980 http://dx.doi.org/10.1016/0379-7112(81)90037-0

[17] Quintiere J.G. and Grove B.S. Correlations For Fire Plumes National Institute of Standards and Technology. Gaithersburg MD 1998

[18] Karlsson Björn and Quintiere, James G. Enclosure Fire Dynamics” CRC Press. Boca Raton Florida 2000

[19] Zukoski E.E.; Kuboca, Toshi and Cetegen Baki Entrainment in the Near Field of a Fire Plume Final Report. California Inst. of Tech., Pasadena, CA NBS GCR 81-346 National Bureau of Standards, Gaithersburg, MD 1981

[20] Heskestad G Luminous Heights of Turbulent Diffusion Flames Fire Safety Journal Vol 5 pp103105,1983

[21] Heskestad G Virtual Origins of Fire Plumes Fire Safety Journal Vol 5 pp109-114 1983

[22] Heskestad G Engineering Relations for Fire Plumes Fire Safety Journal Vol 7 pp25-32,1984 http://dx.doi.org/10.1016/0379-7112(84)90005-5

[23] Heskestad G. Fire Plumes, Plume Height and Air Entrainment SFPE Handbook for Fire Protection Engineers $3{ }^{\text {rd }}$ ed, National Fire Protection Association, Quincy, MA.2002

[24] Thomas, P.H., Hinkley, P.L., Theobald, C.R. and Simms, D. L. Investigations into the Flow of Hot Gases in Roof Venting London. HMSO. 1963

[25] Rouse, H., Yih, C.S. and Humphreys, H.W. Gravitational Convection From a Boundary Source Tellus Vol4 No3 pp201-210. 1952 
[26] Ricou F.P. and Spalding, D.B. Measurements of Entrainment by Axisymetric Turbulent Jets Journal of Fluid Mechanics Vol 11 No 1 pp 21-32 1961 http://dx.doi.org/10.1017/S0022112061000834

[27] Rasbash D.J., Rogowski, Z.W. and Stark, G.W.V. Properties of Fires in Liquids Fuel Vol 35 No 1 pp94-107 1956

[28] Hansell G.O. Heat and Mass Transfer Processes Affecting Smoke Control in Atrium Buildings PhD Thesis, Southbank University 1992

[29] Morgan H P and Marshall N R Smoke Hazards in Covered Multi-level Shopping Malls: An Experimentally-based Theory for Smoke Production. BRE Current Paper 48/75, BRE, 1975

[30] Morgan H P The Horizontal Flow of Buoyant Gases Towards an Opening Fire Safety Journal Vol. 11 pp 193-200 1986

[31] Morgan H P and Hansell G O Atrium buildings: calculating smoke flows in atria for smoke control design. Fire Safety Journal, Vol12, pp 9-35, 1987 http://dx.doi.org/10.1016/03797112(87)90013-0

[32] Morgan H P, Ghosh B K, Garrad G, Pamlitschka R, De Smedt J-C and Schoonbaert L R Design methodologies for smoke and heat exhaust ventilation. BRE Report 3681999

[33] Lee, Shao-Lin and Emmons,H. W. A Study of Natural Convection Above a Line Fire” Journal of Fluid Mechanics, Vol.11 No. 3 pp 353-368 1961 http://dx.doi.org/10.1017/S0022112061000573

[34] Thomas, P H 1987 On the Upward Movement of Smoke and Related Shopping Mall Problems. Fire Safety Journal, Vol. 12 pp191-202, 1987 http://dx.doi.org/10.1016/0379-7112(87)90005-1

[35] Poreh M., Morgan, H.P., Marshall, N. R. and Harrison, R. Entrainment by Two-Dimensional Spill Plumes Fire Safety Journal Vol 30 pp1-19 1998 http://dx.doi.org/10.1016/S0379-7112(97)00036$\underline{2}$

[36] Thomas P H, Morgan H P and Marshall N R. The Spill Plume in Smoke Control Design. Fire Safety Journal, Vol30, pp 21-46, 1998 http://dx.doi.org/10.1016/S0379-7112(97)00037-4

[37] Morgan H P and Marshall N R. Smoke control measures in a covered two storey shopping mall having balconies and pedestrian walk way. BRE Current Paper 11/79, BRE, 1979

[38] Law Margaret A Note on Smoke Plumes From Fires in Multi-level Shopping Malls. Fire Safety Journal, vol 10 pp 197-202 1986 http://dx.doi.org/10.1016/0379-7112(86)90016-0

[39] Harrison R 2004 Smoke Control in Atrium Buildings: A Study of the Thermal Spill Plume M Eng Thesis, Canterbury University 2004

[40] Harrison R and Spearpoint M Spill Over Fire prevention \& Fire Engineers Journal July pp33-35 2005

[41] Hinkley P L Some Notes on the Control of Smoke in Enclosed Shopping Malls Fire Research Note 875 Fire Research Station Borehamwood 1975

[42] Fire Research Station PD284/92 'Design Fires for Smoke Ventilation in Retail Areas Fitted with Fast Response Sprinklers’ 1992

[43] Jeremy Gardner Associates Class Relaxation for Shopping Centres - Fire Engineering Review Report F347/R1 Issue No. 51998

[44] Butcher Gordon E and Parnell Alan C Fire Engineering Solutions in Fire Safety Engineering Vol 3No 4 pp24-25 1996

[45] AS 1668.3 The use of ventilation and air conditioning in buildings Part 3: Smoke control systems for large single compartments or smoke reservoirs Standards Australia Sydney NSW 2001 
[46] Rein G. et al A Priori Modelling of Fire Test One The Dalmarnock Fire Tests: Experiments and Modelling Rein G., Abecassis C., and Carvel R (ed) School of Engineering and Electronics, University of Edinburgh 2007

[47] Wolfram J. et al A Posteriori Modelling of Fire Test One The Dalmarnock Fire Tests: Experiments and Modelling Rein G., Abecassis C., and Carvel R (ed) School of Engineering and Electronics, University of Edinburgh 2007 